Jurnal Mandala Pharmacon Indonesia, Vol 4.No.1 Juni 2018

Avaiable online at www.jurnal-pharmaconmw.com/jmpi

$p$-ISSN : 2442-6032

e-ISSN : 2598-9979

\title{
Uji Aktivitas Antioksidan Ekstrak Metanol Kulit Pisang Raja (Musa Paradisiaca sapientum) Dengan Metode DPPH (2,2-Difenil-1-Pikrilhidrazil)
}

\author{
Sitti Raudhotul Jami' ${ }^{1}{ }^{1}$, Mus Ifaya ${ }^{2}$, Jastria Pusmarani ${ }^{2}$, Eny Nurhikma ${ }^{3}$ \\ ${ }^{1}$ Mahasiswa Ahli Madya Farmasi Akademi Farmasi Bina Husada Kendari \\ 2Program Studi Farmasi STIKES Mandala Waluya Kendari \\ 3Program Studi D-III Akademi Farmasi Bina Husada Kendari
}

\section{ABSTRAK}

Radikal bebas merupakan atom atau molekul yang mengandung satu atau lebih elektron tidak berpasangan dan sangat reaktif sehingga untuk menjadi stabil ia cenderung akan mengambil elektron dari molekul lain yang menimbulkan ketidaknormalan molekul lain dan memulai reaksi berantai yang dapat merusak jaringan. Radikal bebas ini dapat menyebabkan terjadinya penyakit degeneratif seperti kanker, diabetes melitus dan alzheimer. Oleh karena itu, diperlukan senyawa yang dapat meredam efek negatif dari radikal bebas yaitu antioksidan. Pisang Raja mengandung memiliki aktivitas antioksidan. Kulit pisang mengandung antioksidan yang tinggi dibandingkan dengan dagingnya. Tujuan penelitian ini adalah untuk mengetahui aktivitas antioksidan ekstrak kulit pisang raja dengan menggunakan metode uji DPPH (1,1-diphenyl-2picrylhydrazil). Uji aktivitas antioksidan ekstrak

kulit pisang raja dilakukan pada konsentrasi 2,5 ppm, 5 ppm, 7,5 ppm, dan 10 ppm dan vitamin C digunakan sebagai kontrol positif. Absorbansi diukur menggunakan spektrofotometer UV-Vis pada panjang gelombang maksimum yaitu 517 nm. Hasil penelitian ini menunjukkan bahwa ekstrak kulit pisang Raja memiliki aktivitas antioksidan yang sangat kuat dengan nilai $\mathrm{IC}_{50}$ sebesar 46,82 ppm.

Kata kunci: Antioksidan, Ekstrak kulit pisang Raja (Musa paradisiaca sapientum), DPPH

\section{Penulis korespondensi :}

Mus Ifaya

Program Studi Farmasi STIKES Mandala Waluya Kendari

E-mail: ifhifhifayah@gmail.com
\end{abstract}

\section{PENDAHULUAN}

Radikal bebas merupakan atom atau molekul yang mengandung satu atau lebih elektron tidak berpasangan dan sangat reaktif sehingga untuk menjadi stabil ia cenderung akan mengambil elektron dari molekul lain yang menimbulkan ketidaknormalan molekul lain dan memulai reaksi berantai yang dapat merusak jaringan (Fessenden dan
Fessenden, 1986). Radikal bebas secara terus-menerus terbentuk di dalam tubuh. Sebagian besar diperkirakan terlibat dalam berbagai proses penyakit degeneratif (Halliwell, 2012). Senyawa radikal akan merusak sel sehingga menyebabkan suatu penyakit seperti liver, kanker, dan kondisi yang berhubungan dengan umur seperti alzheimer (Hernani 
dan Raharjo, 2006). Oleh karena itu, diperlukan senyawa yang dapat meredam efek negatif dari radikal bebas yaitu antioksidan (Karyadi, 1997).

Salah satu tanaman yang mengandung antioksidan adalah pisang Raja. Kulit pisang Raja mengandung antioksidan lebih tinggi dibandingkan daging buahnya.

Pisang Raja umumnya buahnya yang dimanfaatkan dan kulitnya dibuang. Pemanfaatan kulit pisang (Musa spp.) di Indonesia terbatas, sebagai campuran pakan ternak (20-30\%), serta pupuk kandang dan kompos (60-70\%) (Husni, 2009).

Kulit pisang merupakan sumber senyawa fenol yang merupakan salah satu antioksidan pada kanker dan penyakit hati (Someya et al., 2002). Penelitian yang dilakukan oleh Rose tahun 2013 yang menguji aktivitas senyawa antioksidan dari ekstrak metanol kulit pisang raja (Musa paradisiaca Sapientum) yang dilakukan dengan cara maserasi dengan menggunakan pelarut metanol menyatakan bahwa fraksi metanol kulit pisang raja (Musa paradisiaca Sapientum) menunjukkan positif flavonoid dan fraksi etil asetat memiliki aktivitas antioksidan yang lebih tinggi bila dibandingkan dengan ekstrak metanol dan fraksi nheksan.

Penelitian yang dilakukan oleh Singhal dan Purnima tahun 2013 terhadap aktivitas antioksidan, total flavonoid dan total senyawa fenolik pada ekstrak kulit pisang dengan membadingkan pelarut metanol dan pelarut hexan menyatakan bahwa total flavonoid dan total fenolik ekstrak metanol kulit pisang lebih tinggi dibandingkan ekstrak hexan kulit pisang.

Penelitian ini dilakukan untuk menentukan aktivitas antioksidan dari kulit pisang Raja (Musa paradisiaca Sapientum). Kulit pisang Raja memiliki kulit yang lebih tebal dengan kandungan karoten yang tinggi, dimana karoten merupakan senyawa antioksidan yang memberikan warna kuning pada kulit pisang (Diennazola, 2008).

\section{METODOLOGI PENELITIAN}

\section{Pembuatan Ekstrak Metanol Kulit Pisang} Raja

Pada penelitian ini telah dilakukan ekstraksi kulit buah pisang raja (3 kg). Ekstraksi dilakukan dengan metode maserasi pada suhu kamar dengan pelarut metanol sebanyak 5 L selama 24 jam dan diulangi sebanyak $3 x$. Setelah disaring dengan kertas saring, filtrat yang diperoleh diuapkan pada 
evaporator dengan pengurangan tekanan hingga kental tetapi masih bisa dituang. Penguapan dilanjutkan pada panci Stainless Steel diatas penangas air hingga diperoleh ekstrak kental untuk ditimbang.

\section{Pengujian Aktivitas Antioksidan Ekstrak Kulit Pisang Raja}

Larutan uji esktrak metanol kulit pisang Raja dibuat dengan cara diambil $1 \mathrm{~mL}$ dari masing-masing konsentrasi (2,5 ppm, 5 ppm, 7,5 ppm dan 10 ppm) dan ditambahkan $1 \mathrm{~mL}$ larutan $\mathrm{DPPH}$ konsentrasi $100 \mathrm{mg} / \mathrm{L}$ dan $2 \mathrm{~mL}$ metanol yang kemudian dimasukkan kedalam tabung reaksi lalu diinkubasi selama 30 menit dengan suhu $37^{\circ} \mathrm{C}$. Selanjutnya, serapan diukur dengan panjang gelombang 517 nm. Apabila masingmasing konsentrasi yang diuji memiliki aktivitas antioksidan maka radikal DPPH yang berwarna ungu gelap akan tereduksi menjadi bentuk non radikal yang berwarna kuning. Aktivitas penangkal radikal bebas diekspresikan sebagai persen inhibisi yang dapat dihitung dengan rumus berikut :

\% Inhibisi Radikal DPPH

$=\frac{\text { serapan } \text { blanko }- \text { serapan sampel }}{\text { serapan blanko }} \times 100$

\section{HASIL DAN PEMBAHASAN}

Metode pengujian antioksidan dengan menggunakan DPPH merupakan metode yang paling umum digunakan untuk menguji aktivitas antioksidan sampel secara in vitro dan juga merupakan metode yang sederhana, cepat, serta bahan kimia dan sampel yang digunakan hanya sedikit.

Uji aktivitas antioksidan ekstrak kulit pisang raja dilakukan dengan mengukur nilai aktivitas hambatan terhadap radikal bebas DPPH menggunakan metode spektrofotometri UV-Vis. Prinsip dari metode ini adalah interaksi antioksidan dengan DPPH baik secara transfer elektron atau radikal hidrogen pada DPPH akan menetralkan karakter radikal bebas dari $\mathrm{DPPH}$, jika semua elektron pada radikal bebas DPPH menjadi berpasangan maka warna larutan berubah dari ungu tua menjadi kuning terang.

Untuk mengetahui seberapa besar aktivitas antioksidan ekstrak kulit pisang raja digunakan parameter nilai $\mathrm{IC}_{50}$ (Inhibition Concentration 50\%). $\quad \mathrm{IC}_{50}$ didefinisikan sebagai konsentrasi senyawa antioksidan yang menyebabkan hilangnya 50\% aktivitas DPPH. Hasil pengukuran antioksidan ekstrak kulit 
pisang raja dan vitamin $\mathrm{C}$ berdasarkan $\quad$ DPPH dapat dilihat pada Tabel 1.

hambatan yang diberikan pada radikal

Tabel 1. Persen Penghambat Ekstrak Kulit Pisang Raja dan Vitamin C

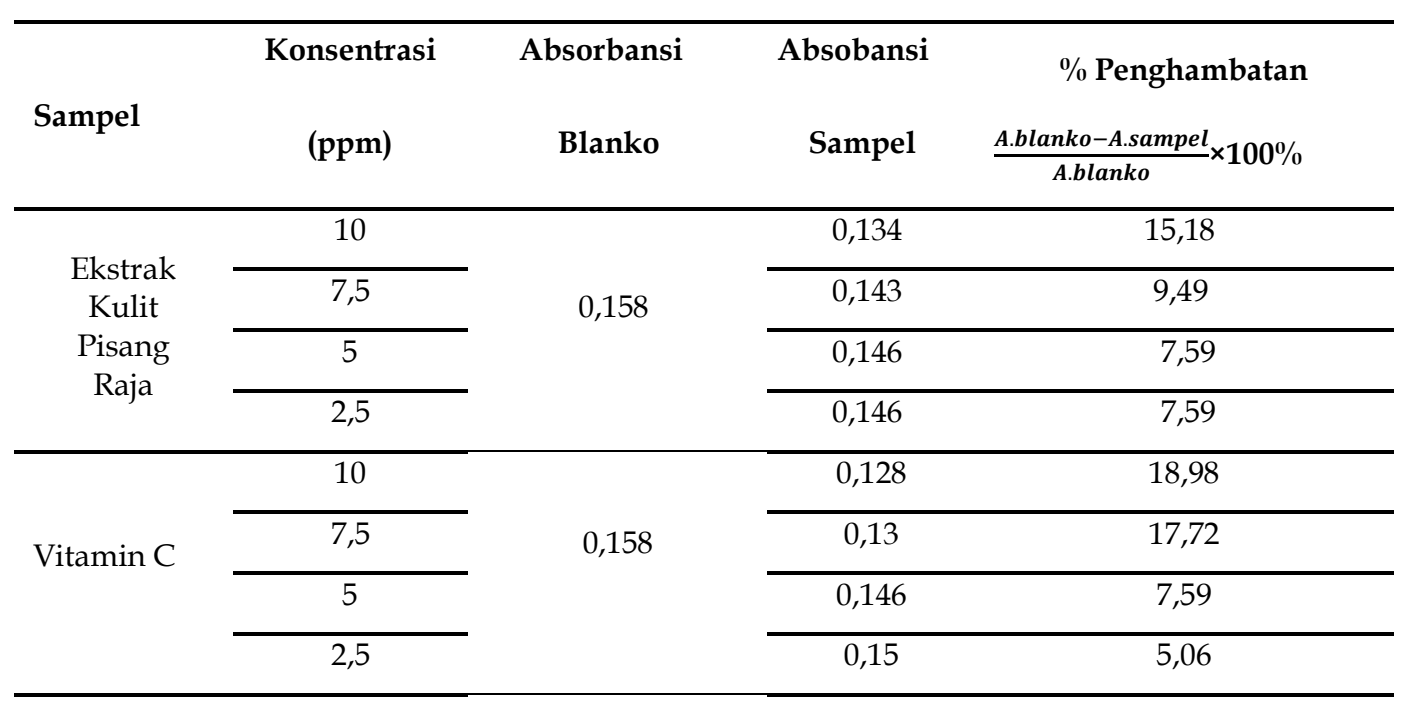

Pada Tabel 1 memperlihatkan

bahwa semakin besar konsentrasi semakin kecil absorbansinya karena semakin besar konsentrasi larutan, aktivitas antioksidan semakin tinggi. Hal ini ditandai dengan semakin pudarnya warna DPPH dan semakin besarnya nilai $\%$ penghambatan.
Setelah mendapatkan data \% penghambatan maka dibuat grafik antara konsentrasi larutan (x) dan \% penghambatan (y). Data persen penghambatan selanjutnya dianalisis menggunkan persamaan regresi linear untuk didaptakan nilai $\mathrm{IC}_{50}$. Berikut persamaan regresi linear ekstrak kulit pisang raja dan vitamin $\mathrm{C}$.

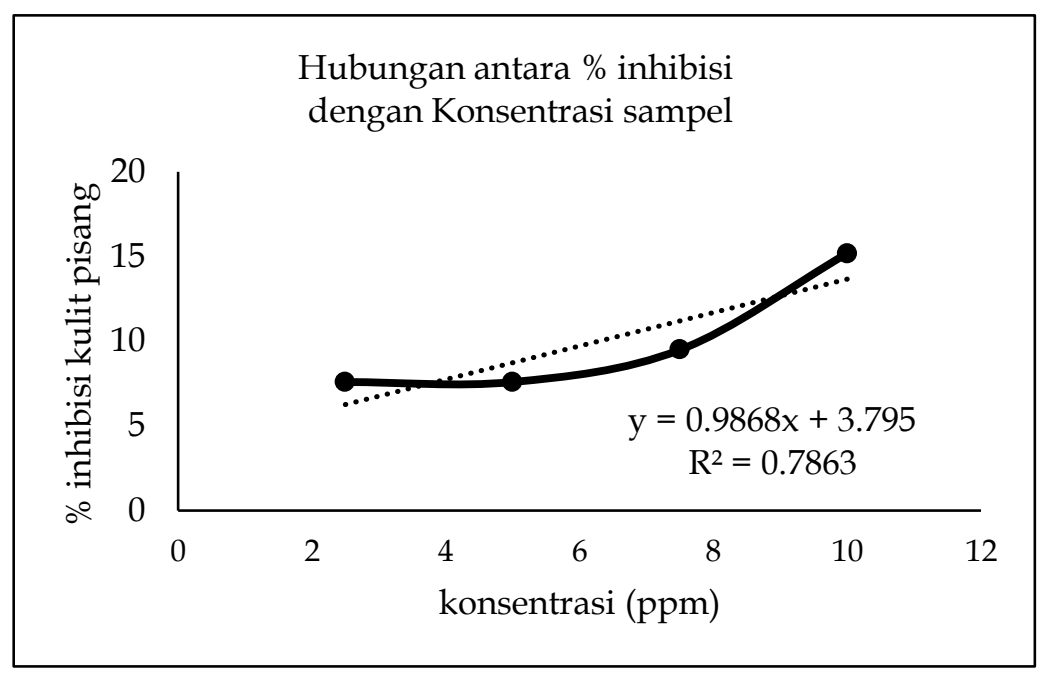

Gambar 1. Persamaan regrasi linear ekstrak kulit pisang Raja 


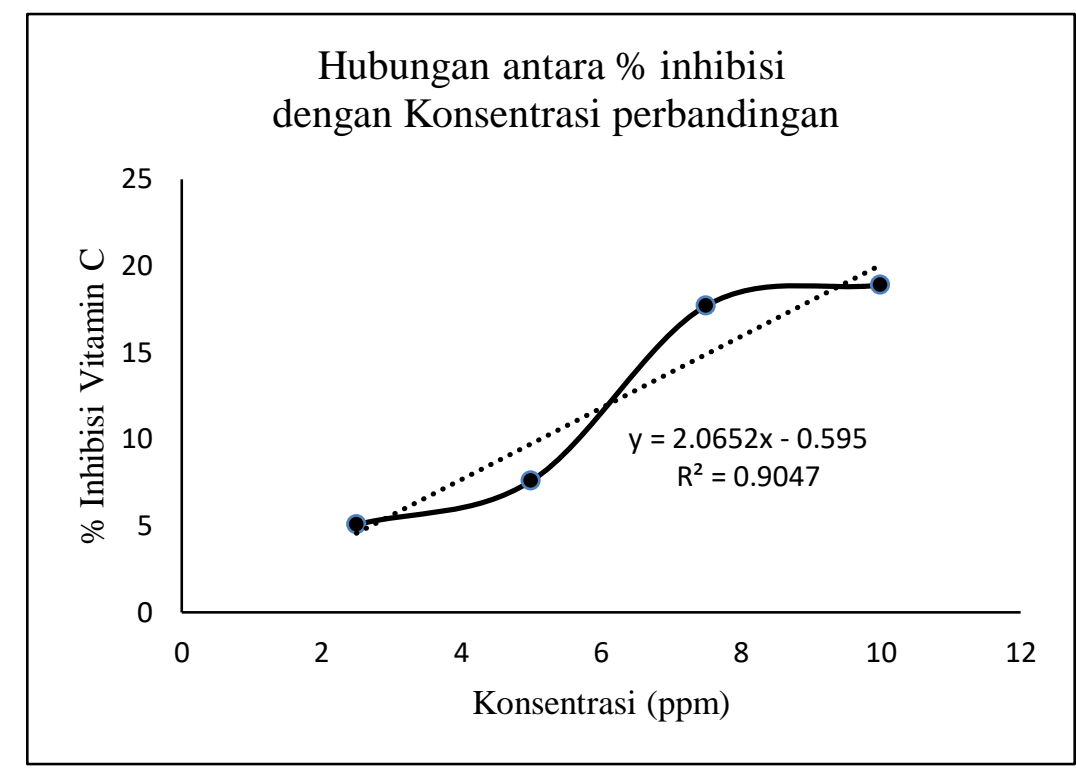

Gambar 2. Persamaan regrasi linear vitamin C

Nilai $\quad \mathrm{IC}_{50}$ ditentukan menggunakan persamaan regresi linear yang diperoleh. Semakin kecil nilai $\mathrm{IC}_{50}$ maka semakin besar aktivitas antioksidan
(Molyneux, 2004). Hasil persamaan regrasi linear, diperoleh nilai $\mathrm{IC}_{50}$ ekstrak kulit pisang raja dan vitamin $\mathrm{C}$ seperti pada Tabel 3.

Tabel 2. Nilai $\mathrm{IC}_{50}$ Ekstrak Kulit Pisang Raja dan Vitamin C

\begin{tabular}{ccc}
\hline No. & Sampel & Nilai IC $_{50}(\mathbf{m g} / \mathbf{L})$ \\
\hline 1 & Ekstrak kulit pisang raja & 46,82 \\
\hline 2 & Vitamin C & 24,49 \\
\hline
\end{tabular}

Tabel 2 menunjukkan bahwa nilai $\mathrm{IC}_{50}$ dari ekstrak kulit pisang raja sebesar 46,82 ppm sedangakan nilai $\mathrm{IC}_{50}$ vitamin C jauh berbeda dengan ekstrak kulit pisang raja yaitu sebesar 24,49 ppm. Aktivitas antioksidan ekstrak kulit pisang raja dan vitamin $\mathrm{C}$ sama-sama tergolong sebagai antioksidan sangat kuat. Menurut Molyneux (2004), suatu senyawa antioksidan dikatakan sebagai antioksidan yang sangat kuat apabila nilai $\mathrm{IC}_{50}$ kurang dari $50 \mathrm{mg} / \mathrm{L}$, kuat apabila nilai $\mathrm{IC}_{50}$ 50-100 mg/L, sedang apabila nilai IC $_{50}$ 100-150 mg/L, lemah apabila nilai $\mathrm{IC}_{50}$ antara $150-200 \mathrm{mg} / \mathrm{L}$, dan sangat lemah bila nilai $\mathrm{IC}_{50}$ lebih dari $200 \mathrm{mg} / \mathrm{L}$.

Aktivitas antioksidan yang sangat kuat karena kulit pisang raja banyak mengandung senyawa bioaktif seperti flavonoid. Senyawa flavonoid merupakan metabolit sekunder yang tersebar pada tumbuhan dan termasuk senyawa fenolik sehingga cenderung mudah larut dalam pelarut polar (Nabavi et al., 2011). Flavonoid bersifat antioksidan sehingga 
mampu meredam aktivitas radikal hidroksil (Sidana et al., 2013).

\section{KESIMPULAN}

Berdasarkan

penelitian

menunjukkan bahwa ekstrak kulit pisang Raja memiliki aktivitas antioksidan dengan nilai $\mathrm{IC}_{50}$ sebesar 46,82 ppm.

\section{DAFTAR PUSTAKA}

Diennazola, R. 2008, Pengaruh Sekat dalam Kemasan Terhadap Simpan dan Mutu Buah Pisang Raja Bulu, Departemen Agronomi dan Hortikultura Institut Pertanian Bogor Mutu Buah Pisang Raja Bulu Fessenden R.J., dan J.S. Fessenden , 1986, Kimia Organik Edisi Ketiga, Jilid I, Erlangga: Jakarta.

Halliwell, B. 2012, Free Radicals and Antioxidant, Updating a Personal View, Nitrion Review 70 : 257-265

Hernani dan Raharjo, 2006, Tanaman Berkhasiat Antioksidan, Penebar Swadaya: Jakarta.

Husni, I., 2009, Prespektif Industri Pisang Terpadu (Guna Peningkatan Nilai Tambah Komoditas), Direktorat budidaya Tanaman Buah Direktorat Jenderal Hortikultura

Departemen Pertanian, http:/ / ditbuah.hortikultura.deptan .go.id//index.php?

option $=$ com_content\&task $=$ view $\&$ i d=118\&Itemid=1, 20 Februari 2015.

Karyadi E., 1997, Antioksidan: Resep Awet Muda dan Umur Panjang From Uji Aktivitas Antiradikal dengan Metode DPPH dan Penetapan Kadar Phenol Total Ekstrak Daun Keladi Tikus ( Thyponium divarcatum (Linn.) Decne), Pharmacon, 6 (2): 51-56.

Nabavi S.F., et al. 2011, Antioxidant Activity of Wild Medlar (Mespilus germanical) Fruits, Stem Bark and Leaf, African Journal of

Biotechnology, Vol. 10(2): 283-9

Molyneux, P. 2004, The Use of The Stable Free Radical Diphenylpicryl-hydrazyl (DPPH) for Estimating Antioxidant Activity, Songklanakarin J. Sci. Technol, 26(2) : 211-219

Singhal, M., and Purnima, R., 2013, Antioxidant activity, Total Flavonoid and Total Phenolic Content of Musa Acuminate Peel Extracts, Global Journal of Pharmacology, 7 (2): 118-122. Someya, S., Yoshiki, Y., and Okubo, K., 2002, Antioxidant Compounds from Bananas (Musa cavendish), Food Chemistry, 79 (3):351-354. 